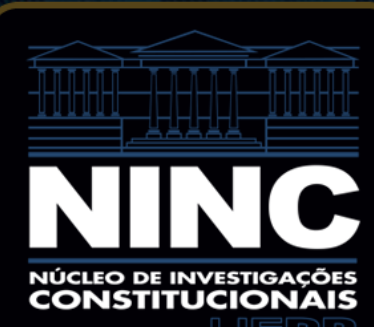




\section{Desenhos institucionais no constitucionalismo contemporâneo}

\section{Institutional designs in the contemporary constitutionalism}

A implementação de um projeto constitucional consiste em tarefa complexa e desafiadora, em especial quando se está a tratar de Constituições forjadas sob a égide de sociedades democráticas, que nelas imprimem valores e objetivos muitas vezes contrastantes ou mesmo antagônicos. A escolha das prioridades a serem adotadas entre as diversas metas traçadas pelo sistema constitucional; a eleição entre os princípios que devem prevalecer em um caso concreto que envolva colisão; a decisão a respeito de qual órgão tem competência para apreciar uma questão constitucional intrincada; a verificação das hipóteses em que determinados entes devem prestar deferência a outros, bem como das situações em que a revisão da decisão de um órgão deve ser levada a efeito por outro... todas essas são questões candentes no constitucionalismo contemporâneo.

Daí a importância de se estudar a fundo as instituições traçadas pelas Constituições para emprestar efetividade às decisões fundamentais plasmadas na ordem constitucional. É por meio do desenho institucional delineado pelo poder constituinte que podem ser encontradas as respostas às difíceis problemáticas acima referidas. A partir de diferentes perspectivas, os trabalhos concentrados nesta edição exibem alguns dos esquemas institucionais tracejados por distintos sistemas constitucionais para dar concretude aos seus preceitos, enfrentando temas como o direito a um julgamento justo

Como citar este editorial | How to cite this editorial: HACHEM, Daniel Wunder. Editorial: Desenhos institucionais no constitucio nalismo contemporâneo. Revista de Investigações Constitucionais, Curitiba, vol. 2, n. 2, p. 4-6, maio/ago. 2015. DOI: http:// dx.doi.org/10.5380/rinc.v2i2.44822. 
na estrutura da União Europeia; as dimensões do Estado Social para a efetivação dos direitos fundamentais sociais; a eleição popular indireta dos altos funcionários na Venezuela; a postura ativista dos juízes e as suas relações com a atividade legiferante; as candidaturas independentes de partidos políticos no México; o acesso à informação pública no Uruguai; os impactos do fenômeno da corrupção na estrutura do Poder Judiciário; as exigências constitucionais para a instauração de processo de impeachment no Brasil, envolvendo as relações entre Poder Legislativo e Poder Executivo.

O número ora apresentado compõe-se de artigos científicos escritos em 3 idiomas diferentes (inglês, espanhol e português), desenvolvidos por pesquisadores filiados a 8 instituições de 6 países distintos (Espanha, Venezuela, Argentina, México, Uruguai e Brasil - São Paulo e Rio Grande do Sul). Dos artigos publicados nesta edição, 100\% são de Professores Doutores, 75\% redigidos em língua estrangeira, 75\% de autores estrangeiros e 100\% de autores exógenos ao Estado do Paraná. São eles:

- The right to a fair trial in the European Union: lights and shadows

\section{Susana Galera Rodrigo}

Profesora Titular de Derecho Administrativo de la Universidad Rey Juan Carlos (Madrid, España)

- Dimensiones del Estado Social y derechos fundamentales sociales

\section{Jaime Rodríguez-Arana Muñoz}

Profesor Catedrático de Derecho Administrativo en la Universidade da Coruña (La Coruña, España)

- La elección popular indirecta de altos funcionarios del Estado en Venezuela y su violación por el Estado autoritario: el golpe de Estado de diciembre de 2014 dado con las inconstitucionales designaciones de los titulares de las ramas del Poder Público

\section{Allan Brewer-Carias}

Profesor de la Universidad Central de Venezuela (Caracas, Venezuela)

- ¿Jueces legisladores?

\section{Estela B. Sacristán}

Profesora de Derecho Administrativo en la Universidad Católica Argentina (Buenos Aires, Argentina)

- Las candidaturas independientes en México

\section{Luis Antonio Corona Nakamura}

Profesor en los programas de Licenciatura, Maestría y Doctorado en Derecho de la Universidad de Guadalajara (Guadalajara, México)

\section{Genaro Hernández Velazco}

Alumno de la Licenciatura en Derecho en la Universidad Juárez Autónoma de Tabasco (Villahermosa, México) 
- Régimen jurídico de la acción de acceso a la información pública en el Uruguay Pablo Schiavi

Profesor de Derecho de la Información y de Investigación y Documentación en la Facultad de Comunicación de la Universidad de Montevideo (Montevideo, Uruguay)

- Impactos da corrupção no direito fundamental a uma prestação jurisdicional conforme a justiça constitucional

\section{Rogério Gesta Leal}

Professor Titular do Programa de Pós-Graduação em Direito da Universidade de Santa Cruz do Sul - UNISC (Santa Cruz do Sul-RS, Brasil)

- Dos requisitos jurídicos para a instauração do processo de impeachment do Presidente da República

\section{Pedro Estevam Alves Pinto Serrano}

Professor de Direito Constitucional e de Fundamentos de Direito Público da Faculdade de Direito da Pontifícia Universidade Católica de São Paulo - PUC/SP (São Paulo-SP, Brasil)

O Direito Constitucional na atualidade clama, cada vez mais, pela pesquisa dos meios institucionais adequados para dar operatividade à dinâmica dos sistemas constitucionais. A inter-relação entre os poderes constituídos, a lógica da estruturação da maquinaria constitucional, o diálogo constante entre os diferentes órgãos e polos de decisão política são temas centrais a ocupar a agenda do constitucionalismo contemporâneo.

Curitiba, maio de 2015.

\section{Prof. Dr. Daniel Wunder Hachem}

Coordenador Editorial da Revista de Investigações Constitucionais 